Cita bibliográfica: Gutiérrez Cruz, M., Such Devesa, M. J. y Gabaldón Quiñones. P. (2021). Factores de éxito en el emprendimiento femenino turístico rural en Costa Rica. Investigaciones Turísticas (22), pp. 148-175. https://doi. org/10.14198/INTURI2021.22.7

\title{
Factores de éxito en el emprendimiento femenino turístico rural en Costa Rica
}

\section{Success factors of women's entrepreneurship in rural tourism in Costa Rica}

Merlyn Gutiérrez Cruz iD, Universidad de Alcalá , España

merlyn.gutierrez.cruz@una.ac.cr

María Jesús Such Devesa iD, Universidad de Alcalá , España

miesus.such@uah.es

Patricia Gabaldón Quiñones (iD, IE Business School. IE University, España

patricia.gabaldon@ie.edu

\section{RESUMEN}

Este artículo de investigación tiene como objetivo definir el perfil de las mujeres emprendedoras costarricenses en el sector del turismo rural y determinar si sus características y las de sus empresas están relacionadas con su desempeño. Se adoptó una metodología mixta basada en entrevistas semiestructuradas y en profundidad. Los resultados ponen de manifiesto la importancia del apoyo familiar y la afiliación a redes como elementos esenciales para el desarrollo de empresas exitosas. La familia y las redes proporcionan dos elementos esenciales para el éxito de las emprendedoras: acceso a la financiación y formalización de sus negocios. Es de especial relevancia destacar la contribución de esta investigación a un campo poco estudiado como es el de las emprendedoras rurales, dados sus aportes a la reducción de la pobreza y en el que tradicionalmente el acceso a la información ha sido muy limitado.

Palabras clave: desempeño; mujeres empresarias rurales; turismo; costarricenses.

\section{ABSTRACT}

This research article aims to define the profile of Costa Rican women entrepreneurs in the rural tourism sector and to determine whether their characteristics and those of their ventures are related to their performance. A mixed methodology has been adopted based on semi-structured and in-depth interviews. The results highlight the importance of family support and contact networks as essential elements for the development of successful enterprises. Family and networks provide two essential elements for the success of women entrepreneurs: access to finance and the formalization of their business. It is particularly important to point out 
the contribution of this research to the under-studied field of rural entrepreneurs, given their contributions to reducing poverty for which access to information has traditionally been very limited.

Keywords: performance; rural women entrepreneurs; tourism; Costa Ricans.

\section{INTRODUCCIÓN}

La creación de empresas es importante para el desarrollo económico de un país, dado que promueve el empleo, la innovación y la generación de riqueza (Fuentes y Sánchez, 2010). En los últimos años, el interés por las micro, pequeñas y medianas empresas (mipymes) ha aumentado debido a la contribución que éstas realizan para el desarrollo económico, sociocultural y ambiental de las naciones (Hernández et al., 2008).

En esta misma línea, el incremento en la tasa de participación empresarial femenina en economías emergentes y desarrolladas ha impulsado la realización de investigaciones empíricas interdisciplinarias sobre las mujeres emprendedoras, centradas en sus características, motivaciones, problemática, aporte económico y social, y su comparación con las empresas dirigidas por hombres, entre otros (Brush, 1992; De Vita et al., 2014; Henry et al., 2015). Se ha encontrado que, las pequeñas empresas propiedad de mujeres en áreas rurales representan una opción de alivio a la pobreza (Bowale et al., 2014).

En Costa Rica, las mipymes representan un 93,3\% del parque empresarial y aportan el 27,7\% del empleo (Brenes et al., 2017). Según el informe GEM 2014 para el país, un 11,2\% de mujeres se encuentran emprendiendo en etapas iniciales y un 1,8\% poseen emprendimientos establecidos, comparado con un $11,6 \%$ y un $3,2 \%$ respectivamente, en el caso de los hombres (Lebendiker et al., 2015).

El turismo permite a las mujeres emprendedoras de las zonas rurales a contribuir a su producción y productividad y refuerza el empoderamiento de las mujeres como propietarias de empresas. En esta línea, el turismo contribuye al cumplimiento de los Objetivos de Desarrollo Sostenible (ODS) número 1, 5, 8, 12 y 14, por su capacidad para reducir la pobreza, generar empleos decentes y promover la realización de las actividades de forma sostenible fomentando la cultura y tradiciones locales. Además, genera uno de cada diez empleos en el mundo. Esto hace que esta industria sea especialmente importante en los países en desarroIlo, debido a su capacidad para empoderar a las poblaciones vulnerables, como las mujeres y las comunidades rurales (Organización Mundial del Turismo [OMT], 2018).

La relevancia de las mujeres empresarias costarricenses en el turismo rural y sus emprendimientos es doble. En primer lugar, a pesar de la importancia de las pymes para el desarrollo económico y de que Costa Rica cuenta con las características adecuadas para fomentar su crecimiento, existe poca información sobre ellas y su funcionamiento (Ramírez, 2010). Actualmente, no se dispone de estadísticas e información clara del total de mipymes costarricenses dedicadas al turismo en el medio rural ni de las que son dirigidas por mujeres. 
En segundo lugar, es necesario conocer de manera específica las características de las emprendedoras rurales y cómo su desempeño es afectado para la formulación de políticas y proyectos que fortalezcan su actividad, fomenten la competitividad y el crecimiento.

Debido a esta brecha de información, este estudio adopta la teoría basada en los recursos (Barney, 1991) e investiga la relación entre el acceso a financiación, formación y afiliación a redes y el desempeño de las micro y pequeñas empresas de turismo rural dirigidas por mujeres en Costa Rica. Para ello, esta investigación buscar abordar la siguiente pregunta: ¿En qué manera los recursos individuales de las empresarias y de sus micro y pequeñas empresas de turismo rural en Costa Rica afectan el desempeño de su empresa?

En este sentido, la selección del desempeño como variable dependiente en la investigación es especialmente relevante. Las investigaciones anteriores han utilizado el desempeño como un indicador para las mujeres empresarias debido a su relación con los beneficios derivados de las empresas dirigidas por mujeres, ya que estas empresas suelen tener menores costos operativos y menores niveles de ventas, ganancias y empleo (Coleman, 2007; Hallak et al., 2015; Lerner y Haber, 2001; Watson, 2003). El desempeño, definido como una medida tanto de la rentabilidad como de las ventas, permite comprender los rendimientos positivos generales de la empresa, alejándose de los indicadores meramente financieros de ganancias.

\section{EL CONTEXTO COSTARRICENSE}

El turismo es una de las actividades económicas más importantes de Costa Rica. En el año 2017, el país casi triplicó las cifras de ingreso de turistas con las que se inició el siglo XXI, al recibir 2.925.128 turistas (Instituto Costarricense de Turismo [ICT], 2018a), frente a los 1.088.075 que lo visitaron en el año 2000 (ICT, 2009). Esto generó US\$ 3.864,1 millones de dólares, superando la aportación de las exportaciones de café, banano, piña y productos farmacéuticos en su conjunto (ICT, 2018b). Además, se estima que un $11,3 \%$ de los turistas realizaron actividades de turismo rural comunitario durante su estancia en el país en el periodo 2013-2017 (ICT, 2018c), lo que pone de manifiesto el creciente interés de los viajeros hacia este tipo de turismo.

Este crecimiento de la actividad turística costarricense ha favorecido la creación de empleos. En el 2016, generó un 8,8\% de empleos relacionados con productos característicos del turismo y un $4,4 \%$ en servicios vinculados al turismo. De estos un $3,49 \%$ de los empleos directos y un $2,48 \%$ de los indirectos los ocupan las mujeres (Banco Central de Costa Rica [BCCR], 2018). Es en el caso de las actividades relacionadas indirectamente con el turismo donde se da una mayor participación de las mujeres.

De acuerdo con estudios realizados por Ferguson (2010), el empleo en el sector turístico centroamericano, que incluye Costa Rica, se caracteriza por la incorporación de la mujer en tareas que reproducen los roles tradicionales del hogar a cambio de salarios mal remunerados y en puestos de baja cualificación. Por otro lado, la propiedad de los negocios aún se estructura por razón de género, etnia y clase, siendo los esposos u otros miembros varones del núcleo familiar quienes figuran como titulares de los emprendimientos. 
El turismo rural surge en Costa Rica en los años 90, ante la demanda de nuevos productos que diversificaran el modelo turístico tradicional de sol y playa. En sus orígenes, se utilizan diversos conceptos para referirse a las actividades turísticas desarrolladas en espacios rurales y relacionadas con el ecoturismo como son el agroecoturismo y el agroturismo, que se basaron en la conservación y el aprovechamiento del patrimonio natural y cultural local y estaban vinculadas directamente a las actividades productivas de las familias y de los pobladores locales que con apoyo financiero de la cooperación internacional establecieron sus primeros emprendimientos turísticos rurales (Chavarría, 2009).

Por otra parte, Cardín Pedrosa y Álvarez López (2007), sugieren que en 1992 se comienza a utilizar el concepto de turismo rural asociado a la reactivación de actividades productivas sostenibles por parte de cooperativas de autogestión que habían recibido donaciones de terrenos del Instituto de Desarrollo Agrario (IDA) en Costa Rica y que, en 1994 crean el Consorcio Cooperativo Red Ecoturística Nacional (COOPRENA) para ofertar paquetes turísticos de turismo rural en el mercado nacional.

La consolidación de la oferta de turismo rural comunitario en Costa Rica se da a principios del año 2000 (Colin y Aldekozea, 2004), lo que llevó a la formación de la Alianza para el fortalecimiento del Turismo Rural Comunitario (TRC) en el año 2004, integrada por instituciones involucradas directamente con la actividad como COOPRENA, la Mesa Campesina, el ICT, el Programa de las Naciones Unidas (PNUD), la Asociación Centroamericana para la Economía, la Salud y el Ambiente (ACEPESA) y la Asociación Costarricense de Turismo Rural Comunitario (ACTUAR) que buscaban cooperar entre ellas, lograr el apoyo de las instituciones públicas y la definición de políticas públicas que apoyaran el desarrollo del TRC (Solano Pacheco, 2006).

El trabajo coordinado de la Alianza da sus frutos con la firma del Decreto que en 2006 declara de Interés Público el TRC, posteriormente en 2009 se crea la Ley No. 8724 de Fomento del TRC y en 2010 su Reglamento.

La oferta de turismo rural costarricense se encuentra estructurada en grupos organizados en asociaciones o cooperativas; en empresas desarrolladas en grandes fincas, que buscan diversificar la actividad agrícola mediante el agroturismo y en empresas lideradas por pequeños productores o campesinos, que diversifican su actividad principal mediante proyectos turísticos, en algunos casos familiares (Chavarría, 2009).

Las actividades que se incluyen dentro de la oferta de turismo rural son: cosecha y recolección de alimentos, observación de aves, visita a mariposarios y jardines botánicos, paseos a caballo, pesca en ríos o estanques, muestras artesanales, observación de prácticas de ordeña y elaboración de quesos, manejo del caballo, paseos en bote, caminatas, paseos en carreta, observación de procesos industriales, gastronomía típica, alimentación de animales, juegos populares, entre otras (Chavarría, 2009).

EI ICT, ente rector de la actividad turística del país clasifica las actividades de turismo rural que obtienen declaratoria turística en posadas de turismo rural comunitario, agencias de viajes receptivas especializadas en ofertas rurales, fincas de actividades temáticas y servicios de alimentos y bebidas criollas o tradicionales (Asamblea Legislativa de la República de Costa Rica, 2009). El elemento distintivo entre las empresas de turismo rural y de turismo rural 
comunitario (TRC) es que, en estas últimas la población local participa a través de organizaciones de base, asociaciones o cooperativas, que son las que gestionan la actividad turística (Calderón Fallas, 2017).

Tabla 1. Posadas de TRC y actividades temáticas por unidad de planeamiento

\begin{tabular}{ccc}
\hline Unidad de planeamiento & Posadas de TRC & Actividades temáticas \\
\hline Guanacaste & 3 & 20 \\
Puntarenas & 3 & 15 \\
Pacífico Central & 0 & 7 \\
Pacífico Sur & 9 & 3 \\
Caribe & 4 & 9 \\
Llanuras del Norte & 2 & 17 \\
Valle Central & 15 & 34 \\
\hline
\end{tabular}

Fuente: Elaboración propia a partir de M. Quesada, comunicación personal, 5 de octubre de 2020.

De acuerdo con datos del ICT (M. Quesada, comunicación personal, 5 de octubre de 2020), actualmente se encuentran operando 36 posadas de turismo rural comunitario y 105 actividades temáticas con declaratoria turística distribuidas en las siete unidades de planeamiento turístico establecidas en el país (ver Tabla 1).

\section{MARCO TEÓRICO}

La Teoría de los Recursos examina el vínculo entre las características internas y el rendimiento y productividad de una empresa. Las empresas tienen un acceso diferente a los recursos por motivos variados. Los recursos que son heterogéneos, inmóviles, valiosos, raros, imperfectamente imitables y no sustituibles, son los que le dan una ventaja competitiva duradera a una empresa (Barney, 1991). De acuerdo con la Teoría de los Recursos, una mejora en el acceso a los recursos implica una mejora en el proceso de producción (Carro y González, 2012) y, por tanto, en su desempeño.

Dentro de este marco teórico, se entiende que un recurso es cualquier elemento tangible o intangible (Hall, 1992; Hill y Jones, 2005; Wernerfelt, 1984) que pueda considerarse como una fortaleza o una debilidad de una empresa determinada (Caves, 1980). Barney (1991) clasifica los recursos de la empresa en tres categorías: recursos de capital físico, recursos de capital humano y recursos de capital organizacional.

Varios investigadores indican que, estos recursos son determinantes en el desempeño de una empresa ya que permiten establecer estrategias que mejoran su eficiencia y eficacia (Amit y Schoemaker, 1993; Barney, 1991; Grant, 1991; Priem y Butler, 2001; Teece et al., 1997).

En esta misma línea se encontró que, el tamaño de la empresa, el tiempo dedicado a su operación y el capital financiero influyen en el resultado empresarial de las emprendedoras en el sector servicios (Díaz y Jiménez, 2010). Otra investigación mostró que, las empresas 
encabezadas por mujeres y minorías, que poseen menos capital inicial, carecen de experiencia previa y operan en servicios minoristas o personales, tienen un bajo desempeño (Cooper et al., 1997). Por otra parte, se argumenta que la escasez de capital empresarial es una de las principales razones del lento crecimiento y desempeño de los negocios de mujeres (Shaw et al., 2009). Asimismo, la financiación y el establecimiento de objetivos comerciales se determinaron como barreras que restringen el desempeño de los pequeños negocios de mujeres en Sudáfrica (Meyer y Mostert, 2016). En resumen, los recursos individuales y de la empresa son fundamentales para el desempeño de los emprendimientos femeninos.

En este estudio se investiga si el acceso a financiación, formación y afiliación a redes está relacionado con el desempeño de las micro y pequeñas empresas de turismo rural costarricense dirigidas por mujeres.

\subsection{El acceso a financiación de la emprendedora rural}

Partiendo de la Teoría de los Recursos, se entiende que el acceso a la financiación es esencial para el desarrollo emprendedor. En líneas generales, el capital financiero constituido por inyecciones de deuda o capital de fuentes externas (Coleman, 2007), contribuye tanto al crecimiento como a la supervivencia y desempeño de una empresa (Cooper et al., 1997). El acceso al crédito da la oportunidad a las empresas para expandirse, introducir nuevos productos o servicios, contratar nuevos empleados y adoptar nuevas tecnologías que posibilitan el aumento de la productividad y del rendimiento (Coleman, 2007; Tigges y Green, 1994).

Actualmente, la financiación a partir de microcréditos permite que las mujeres accedan a créditos a pequeña escala y permite a las instituciones financieras obtener información sobre el rendimiento y la solvencia de las prestatarias (World Bank, 2012). No obstante, estudios empíricos han encontrado que las mujeres emprendedoras tienen poco capital inicial y una menor participación en financiamiento externo (Brush y Chaganti, 1999; Shaw et al., 2009), lo que puede repercutir en un bajo nivel de desempeño y bajos márgenes de utilidad (Powers y Magnoni, 2010).

Varios factores limitan el acceso de las mujeres al crédito, especialmente en los países emergentes y en las comunidades rurales, como la carencia de las garantías necesarias (derechos de propiedad sobre la tierra y los bienes) o el tamaño pequeño de sus empresas y que mayormente se desempeñan en el sector informal (Demirgüç et al., 2008).

Asimismo, las mujeres emprendedoras se caracterizan por realizar inversiones más conservadoras y su aversión al riesgo (Fletschner et al., 2010). Otras limitaciones que restringen el acceso de las emprendedoras a la financiación son el cobro de tasas de interés diferenciales de las que el sistema financiero ofrece en los créditos a los hombres y la poca variedad de productos financieros dirigidos a ellas (World Bank, 2012).

En distintos estudios se identificó que las mujeres se muestran reacias a solicitar financiación porque creen que serán rechazadas, a pesar de ser probable que se les otorgará el préstamo (Coleman, 2002; Fabowale, 1995). En Israel, aquellos emprendimientos turísticos que fueron apoyados financieramente por fuentes externas gubernamentales o de otro tipo 
tuvieron un mejor desempeño que aquellos que no contaron con el apoyo financiero (Lerner y Haber, 2001).

La falta de recursos financieros o la dificultad para obtenerlos es una de las principales barreras que restringen el éxito del negocio para las mujeres emprendedoras en Sudáfrica (Meyer y Mostert, 2016). Investigadores encontraron que los niveles más altos de capital financiero contribuyeron a la supervivencia, el crecimiento y el desempeño de las empresas (Cooper et al., 1997). Esto coincide con los hallazgos de la investigación realizada entre microempresarios en Jamaica, donde se encontró que a mayor capital financiero aumentaban las ganancias de la empresa (Honig, 1998).

Proposición 1: El acceso a financiación de la emprendedora rural se relaciona positivamente con el desempeño de la empresa.

\subsection{El acceso a formación de la emprendedora rural}

La educación juega un papel importante tanto para el aprovechamiento de las oportunidades individuales, como para la capacidad productiva de las empresas y el bienestar de un hogar (SOFA Team, 2011). Estudios empíricos encontraron que el capital humano, entendido como las habilidades y capacidades desarrolladas a través de la educación formal, la capacitación y la experiencia laboral; estaba directamente relacionado con la productividad y el rendimiento de la empresa (Coleman, 1988; Cooper et al., 1997). En esta misma línea, se considera que la capacitación y la educación pueden contribuir positivamente al crecimiento y desempeño empresarial de las mujeres emprendedoras (Tiwari y Goel, 2017).

En las regiones en desarrollo, las cabezas de familia rurales están en desventaja con respecto a la acumulación de capital humano ya que éstas tradicionalmente han tenido un acceso limitado a los servicios educativos (Anríquez, 2011). Además, en las economías en desarrollo, la carencia de habilidades y capacitación en administración, contabilidad, mercadeo y/o finanzas contribuye a que los emprendimientos femeninos tengan menores dimensiones y posean bajos índices de crecimiento (Powers y Magnoni, 2010).

Investigadores hallaron que el nivel de capacitación y la experiencia del emprendedor están relacionados positivamente con el éxito y desempeño empresarial (Saffu et al., 2008). Igualmente, en un estudio sobre microempresarios en Jamaica, se encontró que los altos niveles educativos contribuyen en la rentabilidad de la empresa (Honig, 1998). Sin embargo, el nivel educativo en el sector informal, por lo general, es bajo, limitándose a la educación básica, y/o conocimientos esenciales de gestión y contabilidad. En ocasiones las emprendedoras desconocen la diferencia entre ganancias y capital, lo que conlleva a un eventual colapso del negocio (Debrah 2007).

Se puede afirmar que la educación tiene un efecto positivo sobre la supervivencia, el rendimiento y el crecimiento de las empresas (Cooper et al., 1997) y esta afirmación es compatible con un estudio que muestra que las empresas administradas por personas con títulos universitarios experimentan resultados favorables en ventas, empleo y ganancias (Pena, 2002). 
De forma similar se encontró que, tanto el nivel educativo como la experiencia previa en gestión eran determinantes de la capacidad de los emprendimientos femeninos para generar ganancias y ser rentables (Coleman, 2007). Por otra parte, la formación empresarial es importante para el buen desempeño de las empresas dirigidas por mujeres, aunque estas no posean educación formal (Meyer y Mostert, 2016).

Proposición 2: El acceso a formación de la emprendedora rural se relaciona positivamente con el desempeño de la empresa.

\subsection{La afiliación a redes de la emprendedora rural}

Las redes de colaboración turísticas de base comunitaria incorporan estrategias colaborativas para coordinar los elementos que conforman el paquete turístico, minimizar los impactos en la cultura local y lograr un beneficio colectivo. Estas redes implementan alianzas que son económicamente rentables y socialmente aceptables para la población local (Burgos y Mertens, 2016). En ocasiones, las emprendedoras dedicadas al turismo rural se agrupan en redes como asociaciones, cooperativas o sociedades; estas formas de emprendimiento colectivo contribuyen a impulsar objetivos comunes y colaborar para beneficio mutuo, lo que a su vez aumenta el poder económico y social de las mujeres (Bakas, 2014).

El emprendimiento colectivo permite el fortalecimiento de la oferta de turismo rural de las emprendedoras porque agruparse les facilita el cumplimiento de los complejos requisitos que deben cumplir para operar (Schmidt et al., 2016).

El desarrollo rural y las ganancias de una empresa pueden aumentar si se construyen sinergias y redes, dentro de las unidades económicas agrícolas o entre los agricultores (Knickel y Renting 2000). En el caso del turismo rural, la presencia de redes fomenta las conexiones entre actores diversos, lo que les permite fortalecer su imagen ante los clientes potenciales y a su vez mejora el rendimiento (Che et al., 2005; Jóhannesson et al., 2003).

Las redes y conexiones son importantes para que las empresarias obtengan información, contactos, recursos y para controlar su entorno (Tigges y Green, 1994). "Las conferencias y reuniones de negocios y profesionales parecen ser buenas oportunidades para estimular las redes sociales y facilitar las sinergias entre los actores involucrados en la agricultura, como productores, desarrolladores, agencias de turismo e instituciones financieras" (Barbieri y Mshenga, 2008, p. 79).

De alguna manera, las pequeñas empresas utilizan las redes principalmente para complementar sus propios recursos limitados (Aldrich y Zimmer, 1986). Las redes de mujeres suelen ser más pequeñas y menos diversas, por lo que poseen menos contactos clave (Brush y Chaganti, 1999).

La agrupación en redes de colaboración genera diferencias en el acceso a los recursos de los emprendedores. Por ejemplo, los emprendedores agroturísticos que participan en asociaciones relacionadas con el negocio tienen un mejor desempeño que los que optan por ofrecer sus productos de forma individual (Che et al., 2005). 
Proposición 3: La afiliación a redes de la emprendedora rural se relaciona positivamente con el desempeño de la empresa.

\section{METODOLOGÍA}

Este documento utiliza un diseño de investigación de método mixto; su uso facilita una mayor comprensión de los problemas de investigación y el análisis de los fenómenos complejos (Creswell, 2014).

Debido a que no existe información de la cantidad de mujeres emprendedoras de turismo rural en Costa Rica, la base de datos para esta investigación se creó a partir de un estudio realizado por el Instituto Nacional de las Mujeres (INAMU). El Instituto desarrolló el proyecto Emprende, desde octubre de 2012 hasta abril de 2018. Su objetivo era el fortalecimiento de las capacidades empresariales de las mujeres para potenciar su autonomía económica. Esta institución proporcionó un listado de 79 contactos (mujeres) que participaron en el proyecto en el área de turismo rural.

En una primera fase, se utilizó el Manual de Clasificación Geográfica del Instituto Nacional de Estadística y Censo para determinar si los emprendimientos seleccionados se ubicaban realmente en espacios rurales, ya que no existe una propuesta única a nivel internacional que defina la clasificación urbano-rural (INEC, 2016). Una vez hecha esta clasificación, la lista se redujo a 50 emprendedoras. De estas, se descartaron las que solo tenían una idea de negocio y las empresas inactivas, por lo que quedaron 39 mujeres emprendedoras con un negocio en funcionamiento. Se solicitó al INAMU la información disponible de la población de estudio (39 emprendedoras) que incluye datos referentes a la edad, nivel educativo, tiempo de operación, nivel de ventas mensuales, capacitación, financiamiento, entre otros. Con esta información se realizó el análisis factorial y de clúster.

En la segunda fase, se realizaron entrevistas individuales semiestructuradas y en profundidad para obtener información más detallada de una muestra del total de las emprendedoras. Se realizó una prueba piloto del cuestionario, durante una feria de emprendimiento realizada el 14 de febrero de 2018, en el Parque Recaredo Briceño, en el cantón de Nicoya, en Guanacaste. Se entrevistó a 3 emprendedoras. Posteriormente, con base en estas entrevistas, se eliminaron ítems repetidos y se modificó la redacción de algunas preguntas para mejorar su comprensión.

Para realizar las entrevistas individuales, del listado de 39 mujeres proporcionado por el INAMU, se seleccionó al azar a 20 empresarias. Sin embargo, por motivos diversos (cancelaciones, ausencias, etc.), no fue posible realizar todas las entrevistas, por lo que se utilizó una muestra no probabilística de 13 empresarias que accedieron a participar. Se les visitó en su lugar de residencia o empresa, entre los meses de marzo y abril de 2018. Las entrevistas realizadas por una de las autoras tuvieron una duración de 30 a 40 minutos cada una. Posteriormente, se realizó una transcripción de las entrevistas y se construyó una base de datos utilizando el software SPSS. La información obtenida en esta fase se utilizó para completar las preguntas no respondidas por las empresarias en los datos proporcionados por el INAMU. Los nombres 
de las entrevistadas fueron reemplazados por un código de identificación para garantizar su anonimato. Esta información se utilizó para sustentar el análisis cualitativo de los clústeres.

\subsection{Variables}

La variable dependiente en este estudio es el desempeño de la empresa, mientras que las variables independientes incluyen la financiación (medida con sí, no o no responde), la formación (medida con sí, no o no responde) y la afiliación a redes (se pregunta si la emprendedora opera de forma individual o grupal [sociedad, asociación o cooperativa]).

La educación se midió preguntando el máximo nivel educativo obtenido, las opciones de respuesta fueron $0=$ ninguno, $1=$ primaria incompleta, $2=$ primaria completa, $3=$ secundaria incompleta, $4=$ secundaria completa, $5=$ universitaria incompleta, $6=$ universitaria completa.

La medida de desempeño se basó en los indicadores: ingresos brutos (ventas mensuales) y ganancias, utilizada en varios estudios (Coleman, 2007; Díaz y Jiménez, 2010; Watson, 2003). Los ingresos se midieron según lo informado por las encuestadas en rangos de ventas mensuales de $1=\$ 0$ a $\$ 176,2=\$ 177$ a $\$ 352,3=\$ 353$ a $\$ 528,4=\$ 353$ a $\$ 528,5=\$ 705$ a $\$ 880$, $6=\$ 881$ a $\$ 1320,7=\$ 1321$ a $\$ 1760,8=$ Más de $\$ 1760,9=$ No sabe, no responde. Las ganancias se midieron según la percepción de las empresarias en una escala ordinal de 5 puntos de 1=genera para reinvertir y diversificar, $2=$ genera para subsistir y para vivir, 3=genera para ahorrar $y$ crecer, $4=$ no genera, $5=$ no responde.

\section{RESULTADOS}

Para esta investigación, se adoptó una metodología mixta. En la primera parte del análisis, se utilizó un enfoque cuantitativo. Dada la amplia variedad de información sobre las emprendedoras y su número limitado (39), se utilizó un análisis factorial para reducir el número de variables que inicialmente se habían considerado y facilitar la interpretación de los resultados. El análisis incluye variables demográficas, sociales, laborales y organizacionales.

Tabla 2. Comunalidades

\begin{tabular}{lcc}
\hline & Initial & Extration \\
\hline Nivel educativo & 1,000 &, 647 \\
Es jefa de hogar & 1,000 &, 809 \\
Tiene personas a cargo & 1,000 &, 723 \\
Individual o grupal & 1,000 &, 692 \\
Tiempo de operación & 1,000 &, 662 \\
Nivel de ventas mensuales & 1,000 &, 771 \\
El negocio genera ganancias & 1,000 &, 738 \\
Ha recibido capacitación & 1,000 &, 833 \\
Ha recibido financiamiento & 1,000 &, 699 \\
Tipo de estructura (formal o informal) & 1,000 &, 694 \\
Nivel de gastos mensuales & 1,000 &, 859 \\
\hline
\end{tabular}

Notas: Método de extracción: análisis de componentes principales. 
El estudio de los factores se realizó sobre las 11 variables que mostraban una mayor variabilidad entre las emprendedoras (Tabla 2), con el fin de caracterizarlas alrededor de sus características y su relación con el desempeño del negocio. Posteriormente, utilizando los factores obtenidos, se realizó el análisis clúster, para determinar las agrupaciones homogéneas de las emprendedoras. En la segunda parte del análisis, se utilizó un enfoque cualitativo que se fundamentó en el análisis de las entrevistas de campo a las emprendedoras, basado en la agrupación de la etapa anterior.

\subsection{Análisis Factorial}

Con el fin de agrupar y reducir las variables que caracterizan a las emprendedoras y sus empresas, se realizó un análisis factorial. El método de extracción utilizado en el análisis factorial es el de análisis de componentes principales.

Del análisis factorial se obtienen cinco factores con valores propios mayores o iguales al valor de las 11 variables iniciales (Tabla 3). Estos cinco factores explicaron en conjunto el $73,90 \%$ de la varianza total. Además, las similitudes entre las variables y los factores tuvieron valores superiores a 0.51 , lo que indica que poseen un alto porcentaje de la variabilidad.

Tabla 3. Matriz de componente rotado

\begin{tabular}{|c|c|c|c|c|c|}
\hline & \multicolumn{5}{|c|}{ Componente } \\
\hline & 1 & 2 & 3 & 4 & 5 \\
\hline & Desempeño & $\begin{array}{c}\text { Responsabilidad } \\
\text { en el hogar }\end{array}$ & $\begin{array}{c}\text { Caract. de la } \\
\text { empresa }\end{array}$ & $\begin{array}{l}\text { Apoyo em- } \\
\text { prendedor }\end{array}$ & Educación \\
\hline Nivel de gastos mensuales & ,806 & ,264 & ,327 &, 069 & 164 \\
\hline Nivel de ventas mensuales & ,805 &,- 141 & 177 &,- 079 &,- 257 \\
\hline El negocio genera ganancias & ,692 & ,398 &,- 287 & ,081 & 109 \\
\hline Es jefa de hogar & ,096 & ,892 & ,004 &,- 065 &,- 021 \\
\hline Tiene personas a cargo & 148 & ,767 & 315 & ,092 & ,074 \\
\hline Individual o grupal &,- 043 & ,243 & ,775 &,- 173 & 028 \\
\hline Tiempo de operación & ,389 &,- 046 & ,702 & 110 &,- 061 \\
\hline Ha recibido capacitación &,- 019 & 111 & 166 & ,888 & 073 \\
\hline Ha recibido financiamiento &, 060 &,- 091 &,- 281 & 768 &,- 135 \\
\hline $\begin{array}{l}\text { Tipo de estructura (formal o } \\
\text { informal) }\end{array}$ &,- 138 & ,332 &,- 076 & 110 & 739 \\
\hline Nivel educativo &,- 118 & 357 &,- 076 & 208 &,- 676 \\
\hline
\end{tabular}

Notas: Método de rotación: Varimax con normalización Kaiser.

El primer factor está compuesto por las variables: nivel de gastos mensuales, nivel de ventas mensuales y el negocio genera ganancias. A este factor se le denominó "desempeño". El segundo factor está conformado por las variables: es jefa de hogar y tiene personas a cargo. A este factor se le llamó "responsabilidades en el hogar". El tercer factor incluye las variables: 
individual o grupal y tiempo de operación. Este factor se denominó "características de la empresa". El cuarto factor se compone de las variables: ha recibido capacitación y ha recibido financiamiento, por lo que se llamó "apoyo emprendedor". El último factor se llama "educación y formalidad", y está integrado por las variables nivel educativo y tipo de estructura.

\subsection{Análisis Clúster}

En este apartado, se aborda la aplicación de la técnica de clúster a la información que se dispone sobre las características de la emprendedora y de la empresa. El análisis clúster es una técnica de análisis multivariante que se utiliza con el fin de clasificar en grupos homogéneos de conglomerados, a individuos o variables con base en las características similares que poseen (Peña, 2013). De acuerdo con Pérez López (2004), previo a la realización de un análisis clúster, deben seleccionarse tres aspectos: "las variables relevantes para identificar a los grupos, la elección de la medida de proximidad entre los individuos y la elección del criterio para agrupar individuos en conglomerados" (p. 419).

En nuestro análisis, como medida de proximidad se utilizó la distancia euclídea al cuadrado y como método aglomerativo se eligió el método de Ward. El método de Ward es un procedimiento jerárquico que une los casos buscando minimizar la varianza dentro de cada grupo y a su vez, maximiza la homogeneidad dentro de los grupos (De La Fuente, 2011).

Para crear los conglomerados se utilizaron las variables resultantes del análisis factorial relacionadas con las características de la emprendedora y de la empresa utilizando la población total de 39 emprendedoras. El análisis de conglomerados reveló la existencia de dos grupos como se puede apreciar en el dendograma (Figura 1).

El primer grupo (se observa en la parte baja del dendograma) se compone de 17 emprendedoras (las filas 12, 29, 2, 7, 9, 30, 6, 8, 5, 24, 19, 39, 32, 37, 1, 23, 17). El segundo grupo (se aprecia en la parte alta) está compuesto por 22 emprendedoras (las filas 22, 18, 38, $36,20,15,11,31,33,10,34,21,16,13,14,4,28,26,35,3,27$, y 25$)$. 
Figura 1. Dendograma



Fuente: Elaboración propia utilizando el software SPSS.

\subsection{Análisis mixto: análisis cualitativo según clústeres}

El análisis del perfil de cada grupo (Tabla 4) muestra que el primer grupo, con 17 mujeres emprendedoras, se puede etiquetar como "emprendedoras con dificultades". Las mujeres que pertenecen a este primer colectivo tienen una edad media de 52 años y la mayoría de sus integrantes son agricultoras.

Algunos investigadores consideran que las mujeres que viven en áreas rurales emprenden en una edad considerablemente mayor que la edad normal de integración de una persona en el mercado laboral, debido a que, deben cumplir con su papel de madres y amas de casa (Gidarakou, 2015; Ling et al., 2013). 
Tabla 4. Perfil de los dos clústeres de mujeres emprendedoras en el área de estudio

\begin{tabular}{|c|c|c|}
\hline $\begin{array}{c}\text { Variables utilizadas para la } \\
\text { agrupación }\end{array}$ & $\begin{array}{l}\text { Emprendedoras con } \\
\text { dificultades }\end{array}$ & $\begin{array}{l}\text { Emprendedoras que } \\
\text { prosperan }\end{array}$ \\
\hline Nivel de gastos mensuales & $\$ 0-\$ 176$ & $\$ 881-\$ 1320$ \\
\hline Nivel de ventas mensuales & $\begin{array}{c}\$ 0-\$ 176(29,41 \%) \\
\$ 353 \text { a } \$ 528(29,41 \%)\end{array}$ & $\begin{array}{c}\$ 0-\$ 176(18,2 \%) \\
\text { Más de } \$ 1760(13,6 \%)\end{array}$ \\
\hline El negocio genera ganancias & $\begin{array}{c}\text { Genera para subsistir y para } \\
\text { vivir }(58,82 \%)\end{array}$ & $\begin{array}{l}\text { Genera para reinvertir y diver- } \\
\text { sificar }(22,73 \%) \\
\text { Genera para subsistir y para } \\
\text { vivir }(22,73 \%)\end{array}$ \\
\hline Es jefa de hogar & Sí & Sí \\
\hline Tiene personas a cargo & Sí & No \\
\hline Individual o grupal & Individual $(88,2 \%)$ & $\begin{array}{l}\text { Individual }(54,5 \%) \\
\text { Grupal }(45,5 \%)\end{array}$ \\
\hline Tiempo de operación & De 1 a menos de 3 años. & Más de 5 años \\
\hline Ha recibido capacitación & Sí & No \\
\hline Ha recibido financiamiento & No & Sí \\
\hline Tipo de estructura & Informal & Informal \\
\hline Nivel educativo & Primaria completa & Primaria completa \\
\hline
\end{tabular}

Fuente: Elaboración propia.

Este grupo se caracteriza por una baja valoración en todos los factores (Tabla 5). Presenta un bajo desempeño, con ventas mensuales entre $\$ 0$ a $\$ 176$ y $\$ 353$ a $\$ 528$ y gastos mensuales entre $\$ 0$ a $\$ 176$. Además, las emprendedoras indicaron que apenas generan ganancias para subsistir y para vivir. Este hallazgo es consistente con lo expresado por Cooper et al. (1997) en su estudio, las empresas propiedad de mujeres tienen más probabilidad de sobrevivir que de crecer.

Depende de la temporada, hay temporadas buenas, pero en general los ingresos mensuales van de US\$O a \$176 (E9).

Tabla 5. Resultados de análisis clúster

\begin{tabular}{|c|c|c|c|c|c|}
\hline $\begin{array}{l}\text { Ward } \\
\text { Meth- } \\
\text { od }\end{array}$ & $\begin{array}{c}\text { REGR factor score } \\
1\end{array}$ & $\begin{array}{c}\text { REGR factor score } \\
2\end{array}$ & $\begin{array}{c}\text { REGR factor score } \\
\mathbf{3}\end{array}$ & $\begin{array}{c}\text { REGR factor score } \\
4\end{array}$ & $\begin{array}{c}\text { REGR factor score } \\
5\end{array}$ \\
\hline 1 &,- 748 &,- 300 &,- 499 & -,208 &,- 113 \\
\hline 2 & ,578 & 232 & 385 & 161 & 087, \\
\hline
\end{tabular}

Notas: Factor 1 = desempeño, 2 = responsabilidades en el hogar, 3 = características de la empresa, 4 = apoyo recibido, 5 = educación y formalidad. 
Las mujeres en el ámbito rural crean negocios de tamaño pequeño que poseen un bajo volumen de ingresos, pero que resultan claves para la supervivencia de la familia (Ballestero et al., 2014; Koutsou et al., 2009). Un problema que se percibió con algunas de las emprendedoras entrevistadas fue que no mantienen cuentas separadas de sus ingresos y gastos del negocio con los de su vida cotidiana.

Las mujeres que pertenecen a este grupo son jefas de hogar, casadas, que tienen personas mayores y menores de edad a cargo y de 3 a 4 dependientes económicos.

Todo lo administro yo. La finca, el cafetal, el tour, la cabaña, el restaurante. Tomo las decisiones, acepto las sugerencias de mi esposo. Mis hijos e hijas y los abuelos maternos y paternos dependen económicamente de mí y de lo que gana mi esposo (tiene ganado) (E6).

Este hallazgo fue consistente con varios estudios previos que revelaron que las mujeres emprendedoras además de desempeñarse en las actividades de turismo rural se encargan de atender las tareas del hogar y cuido de la familia (Ahl et al., 2017; Duarte y Pereira, 2018). Asimismo, se debe señalar que, en ocasiones, las tareas ejecutadas en los emprendimientos turísticos rurales femeninos son una extensión de la ocupación de las mujeres en la economía doméstica.

Sus empresas tienen entre 1 a menos de 3 años de operar. Están constituidas individualmente, se ubican en el hogar y predomina la informalidad. Con respecto al lugar donde las emprendedoras operan sus negocios, se encontraron evidencias similares que indican como característica común de las empresas rurales, que el lugar de operación coincide con el lugar de residencia de las mujeres (Gidarakou, 2015; lakovidou, 2012). Esto se puede atribuir a la habitual búsqueda de las emprendedoras de flexibilidad para encargarse de las labores del hogar y del cuidado de sus hijos o personas a cargo.

En su mayoría estas empresas ofrecen servicios de hospedaje, así como tours locales y fincas integrales. Estos resultados coinciden con quienes señalan que el tipo de actividad característico de las emprendedoras turísticas rurales es la prestación de servicios de alojamiento (Ahl et al., 2017; Perez y Fuller, 2015).

Las emprendedoras que operan informalmente indicaron que se mantienen en esta condición principalmente por la inestabilidad de la actividad.

Vendo queso, natilla y huevos. Hay meses que no llega ningún turista. El turismo no es asiduo. El voluntario es barato. Cobro 3 mil colones el tour. Prácticamente el proyecto no genera ganancias, por lo que no puedo pagar a un contador (E2).

Asimismo, otra de las razones por las que las emprendedoras deciden operar en la informalidad es la burocracia que conlleva iniciar y manejar un negocio, este es un problema importante que enfrentan las mujeres rurales de una edad relativamente alta y con un nivel educativo bajo (Gidarakou, 2015).

Las emprendedoras en este grupo poseen educación primaria completa. Han recibido apoyo en capacitación principalmente por parte del INAMU y del Instituto Nacional de 
Aprendizaje (INA). En su investigación, Duarte y Pereira (2018) sugieren que el turismo rural es una actividad que promueve la igualdad de género y permite la participación de mujeres con baja educación. A pesar de que la mayoría cuenta con educación formal mínima, el acceso a capacitaciones les enseñó cómo gestionar un negocio.

Tenía la idea y tenía todo, pero faltaba, qué puedo hacer con esto. Pero cuando estudié cambió eso, primero ambiental y organización en el INCAE-CATIE (E12).

La participación en el mercado laboral turístico rural les permite a las empresarias con un bajo nivel de estudios mejorar su calidad de vida a medida que ganan experiencia y mejoran su cualificación profesional a través de las capacitaciones recibidas (Duarte y Pereira, 2018).

Así lo expresaron algunas entrevistadas, quienes señalaron que las capacitaciones recibidas les ayudó a verse como empresarias porque en ocasiones ellas no cobraban por sus productos o servicios.

En el proyecto Emprende comencé a visualizar el concepto de empresa, antes decía: se lo regalo (E1).

De forma similar, estudios encontraron que las emprendedoras carecían de habilidades profesionales en el área turística, sin embargo, a través de programas de capacitación fueron adquiriendo los conocimientos básicos requeridos para atender este tipo de negocios (Bakas, 2014; Parsheera y Sood, 2011).

Estas mujeres indicaron que al iniciar el negocio no tenían estudios en turismo, pero gracias a las capacitaciones recibidas han ido prosperando y conociendo el funcionamiento del sistema turístico. También les enseñaron sobre la elaboración de productos y temáticas que pueden formar parte de las actividades que ofertan. Es importante mencionar que los talleres a los que asisten, les enseñan a valorarse y las motivan a empoderarse.

En COOPELDOS nos dieron capacitación sobre el cuido del café (E5).

EI INAMU nos enseñó que somos inteligentes. Que no es cierto que las ideas las tienen otros. Que debe aprender a valorar lo que tiene y ser cada día mejor (E12).

En las áreas rurales normalmente predominan las relaciones patriarcales en el trabajo agrícola, la toma de decisiones, la posesión de la tierra, entre otros aspectos (Gidarakou, 2015); lo que se convierte en un impedimento para el desarrollo de los emprendimientos femeninos. Una de las emprendedoras entrevistadas mencionó que al inicio tuvieron problemas para que sus esposos les permitieran desarrollar la actividad turística, sin embargo, posteriormente al ver los beneficios que la actividad generaba, los hombres las apoyaron y actualmente colaboran.

Estudié derecho de igualdad, de oportunidad, capacitaciones de INAMU para poder enfrentar a los hombres. Después ellos aceptaron, primeramente, mi esposo. Yo soy la fundadora e impulsé a las otras mujeres (E12).

Estas empresarias no recurrieron a préstamos para emprender, por el contrario, utilizaron sus ahorros propios. 
Tenía hijos pequeños y necesitábamos como salir adelante, buscar otra manera de sobrevivir. Después del terremoto, nos botó la casa, perdimos todo. Quedamos en la calle. Me fui a trabajar en la bananera, ahorraba todo lo que se podía, mi esposo se quedó construyendo otra casita y mis hijos estaban en el colegio. Ahorramos lo más que se podía para volver a empezar a comprar todo. Gandoca tiene mucho que ofrecer y está como virgen, no se ha aprovechado todo (E9).

Otras empresarias señalaron que recibieron apoyo de su familia.

Los hijos me dieron el dinero para construir la cocina. $Y$ a puros poquitos. A veces mi hijo gemelo me viene a ayudar, mis hijas, hasta los yernos. No se puede, si compra material no alcanza para pagar mano de obra, si no es con apoyo familiar es imposible (E5).

Las razones que expresaron les dificultan el acceso a créditos bancarios son lo complicado de los requerimientos que solicitan, en ocasiones no cuentan con bienes que sirvan de garantía, la estacionalidad de la actividad y la desconfianza de tener que poner como garantía lo poco que tienen.

No busco financiamiento por desconfianza porque me piden papeles del terreno.

No dependo del banco, de préstamos ni de socios (E7).

Estos resultados coinciden con lo expresado por varios autores, las mujeres generalmente utilizan sus ahorros personales o recurren al entorno familiar para sacar adelante sus emprendimientos, ya que los préstamos bancarios, por lo general, requieren garantías de propiedad y las mujeres no desean arriesgarse a depender de las instituciones financieras o a poner en peligro la propiedad familiar en caso de quiebra (Bock, 2004; Gidarakou, 2015).

Un obstáculo a que se enfrentan estas emprendedoras cada año es la estacionalidad del turismo, debido a que hay meses en que la visitación baja hasta el punto de que no reciben ningún turista.

El negocio es rentable en temporada alta de diciembre a Semana Santa (E7).

Esta problemática ha sido abordada ampliamente por la literatura turística, debido a su efecto disruptivo en la actividad económica de las emprendedoras rurales, que como consecuencia limita el crecimiento de las empresas (Andriotis, 2005; Brunet y Alarcón, 2007).

Algunas empresarias expresaron que, debido al aumento de la competencia, en los últimos años han perdido a las compañías que habitualmente eran sus proveedoras de clientes.

Antes trabajaba con Mambo Tours, suplía a otros Ahora mandan gente a otros lugares (E7).

El grupo 2 está compuesto por 22 mujeres emprendedoras. La edad promedio de estas emprendedoras es 46 años. A pesar de no poseer estudios formales reconocen como su profesión, ser empresarias. Se nombró a este grupo "emprendedoras que prosperan".

Iniciamos por el deseo de superar una comunidad. Las necesidades nos instan a pensar qué más hacer. En la comunidad no hay empleo (E3). 
Este colectivo se destaca por presentar valores positivos, más altos en todos los factores (Tabla 4). Se caracteriza por tener un mejor desempeño, registrar ingresos mensuales entre $\$ 0$ a $\$ 176$ y algunas veces, de más de $\$ 1760$ y generar ganancias para reinvertir y diversificar o para subsistir y vivir. Además, las mujeres indicaron que sus gastos mensuales están entre $\$ 881$ a $\$ 1320$.

Las mujeres crean empresas pequeñas que generan ventas mensuales más bajas debido a que son más cautelosas cuando asumen riesgos (Gidarakou, 2015). Una de las entrevistadas expresa que cuando obtienen más ingresos los utilizan para reinvertir en el negocio.

$Y$ tuvimos que aprender duro para poder atender al turismo y poder usar el ingreso que entraba para mantención de la iguana, hasta que pudimos conseguir un poquito más para pagarle a alguien que nos ayudara en ese tiempo a mantener las iguanitas (E11).

La mayoría de las mujeres en las zonas rurales conviven con su pareja (Ballestero et al., 2014). Las emprendedoras de este grupo son jefas de hogar, casadas, que no tienen personas a cargo, sin embargo, de 1 a 2 personas dependen económicamente de ellas. Así lo expresó una de las entrevistadas:

Mis padres dependen económicamente de mí. (E10).

Sus empresas se caracterizan por tener más de 5 años de antigüedad, ubicarse en el hogar y operar informalmente. Ofrecen principalmente servicios de hospedaje, así como tours locales, fincas integrales y comidas típicas. Esto coincide con estudios que destacan el predominio de pequeñas empresas turísticas rurales femeninas en el sector alojamiento y restauración (Getz y Carlsen, 2005; Jaafar et al., 2015).

El $46 \%$ de los emprendimientos en este clúster está conformado grupalmente (como sociedad, asociación o cooperativa) y el resto trabaja individualmente.

Éramos 15 mujeres de la comunidad. Tres instructoras que explicaban cómo hacer cocinas y cómo se usan. Tres o cuatro personas de la comunidad que apoyaban. Una enseñaba nutrición, comida sana con menos grasa, cómo proteger el ambiente, ventajas de la energía solar, autoestima, derechos de la mujer (E13).

De acuerdo con una investigación realizada en Grecia, las cooperativas de mujeres muestran gran potencial como una forma colectiva de emprendimiento femenino en las áreas turísticas rurales que impulsa el espíritu empresarial (Gidarakou (2015). Se afirma que, "el emprendimiento grupal proporciona una gama de habilidades, la posibilidad de un equipo de gestión equilibrado, fortalezas combinadas y apoyo psicológico" (Koutsou et al., 2012, p.194).

Por otro lado, los vínculos que mantienen con las universidades nacionales y extranjeras, les permite tener un flujo de turistas constante.

Un grupo de estudiantes de la Universidad de Michigan nos visita 3 veces al año.

Se hospedan en casas de asociados. Les vendemos el almuerzo (E10). 
Las emprendedoras que operan informalmente indicaron que se mantienen en esta condición principalmente por la inestabilidad de la actividad.

Tengo como 5 años, que recibo poco, ha bajado, el negocio sobrevive a voluntad de los dioses. Cuando comencé tenía muchos clientes. En el día tenía 10 u 11. En el mes tenía 30 personas o más. Las escuelas a veces visitan. Hay turistas de bares. Hay meses que no llega nadie. Vivo del ahorro que dejó los años atrás. A veces no tenemos cómo comprar el alimento y tuvimos que liberar muchas iguanas. Ahora tenemos 80 pequeños (E11).

Esta misma situación se identificó en un estudio realizado en Brasil, que postula que su formalización contribuiría al fortalecimiento de las empresas y al fomento de un turismo sostenible (Schmidt et al., 2016).

La mayoría de las emprendedoras no recibió apoyo en capacitación, únicamente poseen educación primaria completa.

Así fue como nosotras empezamos cambiando la finca de iguanas que era un proyecto para la comunidad, para familia y no con fines de turismo, pero como todas las familias que se habían anotado se retiraron, solo quedó mi familia, entonces nosotros lo tomamos, dijimos, no lo vamos a dejar caer, entonces así fue como empezamos trabajando sin un colón y viendo lo poquito que encontrábamos y aprendiendo y conociendo porque E11 padece de fobia, me da miedo la gente y hablar (E11).

Estos resultados son consistentes con investigaciones en Grecia e India, donde se identifica que las emprendedoras poseen un bajo nivel educativo, una baja experiencia administrativa y que existe una falta de programas de capacitación útiles (Gidarakou, 2015; Bharathi y Reddy, 2013).

Estas empresarias recibieron financiamiento, procedente principalmente de donaciones. Algunas mencionaron que obtuvieron financiación del Fondo de Fomento para Actividades Productivas y de Organización de las Mujeres (FOMUJERES), que es un fondo no reembolsable que otorga el INAMU para financiar proyectos de actividades productivas dirigidas por mujeres. Esto puede explicar que hayan logrado establecerse y sobrevivir más de tres años.

Cuando nosotros comenzamos nos financiaron todo, biólogo y todo. Los territorios indígenas no pueden decir que los proyectos los financiamos nosotros mismos. Vino financiado por los noruegos dando todo por 4 años (E11).

En el caso de las mujeres emprendedoras que viven en una reserva indígena, indicaron que el problema para el acceso a financiación es que los bancos no prestan a indígenas.

Un obstáculo a que se enfrentan estas emprendedoras cada año es la estacionalidad del turismo, debido a que hay meses en que la visitación baja hasta el punto de que no reciben ningún turista.

Cuando no tenemos visitas no tenemos ingresos. Los meses más visitados son los de la Estación Seca, de diciembre a marzo (E3). 
Algunos autores reconocen que la temporada de visitación en el turismo rural es corta, por lo que se deben generar ingresos en un periodo de tiempo reducido y afrontar la baja en la llegada de turistas con actividades alternativas (Radović y Radović-Marković, 2016; Roberts y Hall, 2001).

\section{DISCUSIÓN Y CONCLUSIONES}

Esta investigación contribuye al conocimiento de las mujeres emprendedoras y las MIPYMES en turismo rural en Costa Rica. El análisis examina las relaciones entre el acceso a las finanzas, la formación y la afiliación a redes de mujeres emprendedoras y el desempeño de sus empresas. Es de especial relevancia destacar la aportación de esta investigación a un campo muy poco estudiado como son las emprendedoras rurales, en el que tradicionalmente el acceso a la información ha sido muy limitado.

Se utilizó un enfoque de método mixto. Primero, se llevó a cabo un análisis factorial seguido de un análisis de conglomerados utilizando las respuestas y características de las empresarias rurales. Durante este proceso, se definieron dos grupos de mujeres empresarias de acuerdo con características comunes compartidas. Estos grupos fueron llamados: mujeres emprendedoras que prosperan y emprendedoras con dificultades.

La primera proposición predice que el acceso a la financiación se relaciona positivamente con el desempeño de la empresa. Sin embargo, dada la agrupación de empresarias, no podemos confirmar esta proposición para todos los grupos. Las emprendedoras turísticas rurales cuyas empresas recibieron financiación, tienen cifras de negocios más altas y reportaron obtener ganancias para subsistir y diversificar. Contrariamente, las mujeres que usaron sus ahorros u obtuvieron apoyo familiar para constituir la empresa, tuvieron ventas bajas y apenas generaron ganancias para subsistir y vivir.

Uno de los aspectos a destacar en este punto es que las emprendedoras que recibieron donaciones por parte de políticas públicas no reportaron obtener altas cifras de ganancias que les permitiera ahorrar. Esto nos lleva a pensar que realmente las emprendedoras que reciben grandes donaciones necesitan de otros "recursos" para que sus empresas funcionen. La provisión de donaciones, únicamente, no genera todo el retorno que se pudiera esperar.

La segunda proposición predice que el acceso a formación de la emprendedora rural se relaciona positivamente con el desempeño de la empresa. En este caso, no podemos afirmar que la formación es un factor determinante para el éxito empresarial de estas micro y pequeñas empresas costarricenses, ya que en ambos grupos la mayoría de las mujeres únicamente tienen educación primaria. Los resultados muestran que las emprendedoras con dificultades, que recibieron capacitación, consiguieron ventas bajas y ganancias para subsistir y vivir. Es interesante resaltar que, el grupo de las emprendedoras relativamente más jóvenes, parecen prosperar, a pesar de que indicaron no recibir capacitación, tuvieron ventas más altas y sus empresas generaron ganancias para subsistir y diversificar.

La tercera proposición predice que la afiliación a redes de la emprendedora rural se relaciona positivamente con el desempeño de la empresa. Se encontró que sí se puede 
confirmar que la afiliación a redes puede contribuir a mejorar el desempeño de las micro y pequeñas empresas. Los resultados revelan que las emprendedoras cuyas empresas están conformadas como una sociedad, una asociación o una cooperativa turística, tuvieron ventas más altas y generaron ganancias para subsistir y diversificar.

El presente trabajo es una primera aproximación a la realidad de las mujeres emprendedoras costarricenses en la actividad turística rural. De alguna manera, los resultados de la investigación ponen de manifiesto la importancia del apoyo familiar y la afiliación a redes como elementos esenciales para el desarrollo de empresas exitosas. La familia y estas organizaciones proporcionan un elemento esencial para el éxito de las emprendedoras: el acceso a financiación.

Las implicaciones de la investigación para las políticas públicas son clave para el desarrollo del emprendimiento rural en Costa Rica. Los resultados revelan cómo el éxito empresarial está esencialmente determinado por el acceso a la financiación. El enfoque tradicional para apoyar a las mujeres emprendedoras se ha puesto en proporcionar capacitación en negocios y gestión. Sin embargo, esta capacitación por sí sola no brinda muchos beneficios a las emprendedoras. Es esencial proporcionarles fondos, simplificar el proceso de acceso al crédito y de registro de la empresa, para que ésta se mueva. De esta manera, una vez que se otorga el acceso a las finanzas, la capacitación y el acceso a las redes, en forma de asociaciones, podrían impulsar a estas empresas a crecer y mejorar su desempeño.

Esta investigación es una primera aproximación para estudiar la realidad de las mujeres emprendedoras que participan en la actividad de turismo rural en Costa Rica, permitiendo comprender las características de las empresarias, sus empresas y su desempeño, como una herramienta para impulsar el empoderamiento de las mujeres, reducir la pobreza, fortalecer la cultura local, reducir el desempleo y diversificar la economía de las comunidades.

Sin embargo, esta investigación no viene sin limitaciones que eventualmente podrían convertirse en futuras vías de investigación. Primero, el tamaño de la muestra es pequeño, aunque ofrezca un gran detalle por parte de cada una de las emprendedoras. Un análisis con una muestra más amplia ayudaría al desarrollo del conocimiento más exhaustivo de cada uno de los elementos que afectan al emprendimiento femenino rural.

Segundo, algunas de las emprendedoras, especialmente las que operan en la informalidad, muestran desconfianza en brindar datos de la empresa, lo que pudo limitar el acceso a información en algunos casos.

Tercero, esta investigación se centra en la Teoría de los Recursos, especialmente en la financiación, la formación y la afiliación a redes, pero futuras investigaciones podrían estudiar otros factores que influyen en el desempeño de la empresa, tales como su ubicación, o los diferentes niveles de formalización.

Cuarto, uno de los elementos subyacentes es la relevancia del asociacionismo entre las emprendedoras rurales y su papel en el crecimiento de sus empresas. Futuras investigaciones podrían profundizar en el análisis de los beneficios de la asociatividad para las mujeres emprendedoras en el sector turístico rural. 
Finalmente, debido a que el acceso a la financiación es un elemento clave de desarrollo y éxito de las emprendedoras rurales costarricenses, futuras investigaciones podrían analizar la situación actual y los beneficios del acceso a microcréditos por parte de estas emprendedoras.

\section{REFERENCIAS BIBLIOGRÁFICAS}

Ahl, H., Berglund, K., Pettersson, K., Sköld, B., y Tillmar, M. (2017, Noviembre 15-17). Entrepreneurship in rural areas: The role of women? Presentado en Conferencia RENT. Lund, Sweden. Recuperado de https://eprints.lancs.ac.uk/id/eprint/127244/1/ RENT_E ship in rural areas the role of women.pdf

Aldrich, H., y Zimmer, C. (1986). Entrepreneurship Through Social Networks. En D. Sexton y R. Smilor (Eds.), The Art and Science of Entrepreneurship (pp. 3-23). Ballinger, New York. Recuperado de https://www.researchgate.net/ publication/291165757 Entrepreneurship Through Social Networks

Amit, R., y Schoemaker, P.J.H. (1993). Strategic assets and organizational rent. Strategic Management Journal, 14(1), 33-46. doi: https://doi.org/10.1002/smj.4250140105

Andriotis, K. (2005). Seasonality in Crete: problem or a way of life? Tourism Economics, 11(2), 207-224. doi: https://doi.org/10.5367/0000000054183478

Anríquez, G. (2011). The State of food and agriculture. Women in agriculture. Closing the gender gap for development 2010-11. Rome: Food and Agriculture Organization of the United Nations, FAO. Recuperado de http://www.fao.org/3/a-i2050e.pdf

Asamblea Legislativa de la República de Costa Rica. (2009). Ley Fomento del Turismo Rural Comunitario No. 8724. San José, Costa Rica: Diario Oficial La Gaceta. Recuperado de http://www.ict.go.cr/es/documentos-institucionales/legislación-de-empresas/ leyes-y-reglamentos/630-ley-fomento-del-turismo-rural-comunitario/file.html

Bakas, F.E. (2014). Tourism, female entrepreneurship and gender: crafting new economic realities in rural Greece (Doctoral dissertation). University of Otago. https://ourarchive. otago.ac.nz/handle/10523/5381

Ballestero, P.T., Romero, P.A., y Serrano, L.G. (2014). Emprendimiento de la mujer en el ámbito rural: el turismo como motor de desarrollo. Esic market, 45(3), 553-604. Recuperado de https://dialnet.unirioja.es/servlet/articulo?codigo $=4939505$

Banco Central de Costa Rica. (2018). Personas en la actividad turística. Cuenta Satélite de Turismo. Recuperado de https://www.ict.go.cr/es/estadisticas/cifras-turisticas.html

Barbieri, C., y Mshenga, P. (2008). The Role of the Firm and Owner Characteristics on the Performance of Agritourism Farms. Sociologia Ruralis, 48(2), 166-183. doi: https://doi. org/10.1111/j.1467-9523.2008.00450.x

Barney, J. (1991). Firm Resources and Sustained Competitive Advantage. Journal of Management, 17(1), 99-120. doi: https://doi.org/10.1177/014920639101700108

Bharathi, G.V., y Reddy, P.H. (2013). A study on rural women entrepreneurship in Vempalli Mandal, Kadapa District, A.P. India. African Journal of Hospitality Tourism and Leisure, 2(3). Recuperado de https://www.researchgate.net/publication/329963916 A study on rural women entrepreneurship in Vempalli Mandal Kadapa District AP India 
Bock, B.B. (2004). Fitting in and Multi-tasking: Dutch Farm Women's Strategies in Rural Entrepreneurship. Sociologia Ruralis, 44(3), 245-260. doi: https://doi. org/10.1111/j.1467-9523.2004.00274.x

Bowale, E.K., Longe, J.B., y Suaibu, O. (2014). Role of female entrepreneurs in poverty alleviation in rural communities: The case of Akoko north-east local government area in Ondo state, Nigeria. En Primorac, D., y Jovancai, A. Economic and Social Development: Book of Proceedings, 133-150. Recuperado de http://m.covenantuniversity.edu.ng/Profiles/ Bowale-Ebenezer/ROLE-OF-FEMALE-ENTREPRENEURS-IN-POVERTY-ALLEVIATION-INRURAL-COMMUNITIES-THE-CASE-OF-AKOKO-NORTH-EAST-LOCAL-GOVERNMENTAREA-IN-ONDO-STATE-NIGERIA

BrenesL., Hernández, V., Bermúdez, L.,yGómez,A. (2017). EstadodesituacióndelasPYMEen Costa Rica 2016. San José, Costa Rica: MEIC. Recuperado de https://www.researchgate.net/ publication/315778750 Estado de Situacion de las PYME_en_Costa_Rica_2016

Brunet, I., y Alarcón, A. (2007). Mujeres emprendedoras en el marco del turismo rural. Revista de Gestión Pública y Privada, 12, 53-74. Recuperado de https://dialnet.unirioja.es/ servlet/articulo?codigo $=3073067$

Brush, C.G. (1992). Research on Women Business Owners: Past Trends, a New Perspective and Future Directions. Entrepreneurship Theory and Practice, 16(4), 5-30. doi: https://doi. org/10.1177/104225879201600401

Brush, C.G., y Chaganti, R. (1999). Businesses without glamour? an analysis of resources on performance by size and age in small service and retail firms. Journal of Business Venturing, 14(3), 233-257. doi: https://doi.org/10.1016/S0883-9026(97)00103-1

Burgos, A., y Mertens, F. (2016). As redes de colaboração no turismo de base comunitária: implicações para a gestão participative. Tourism \& Management Studies, 12(2), 18-27. doi: http://dx.doi.org/10.18089/tms.2016.12203

Calderón, E.G. (2017). Turismo rural comunitario, agricultura familiar y desarrollo rural. Análisis de algunas experiencias en las áreas rurales de Costa Rica. Revista Española de Estudios Agrosociales y Pesqueros, 247, 15-58. Recuperado de https://dialnet.unirioja. es/servlet/articulo?codigo $=6049811$

Cardín, M. y Álvarez, C.J. (2007, 26-28 de septiembre). El Turismo Rural Comunitario en Costa Rica. Actas XI Congreso Internacional de Ingeniería de Proyectos, Lugo. https://www. aeipro.com/files/congresos/2007lugo/ciip07 1658 1666.340.pdf

Carro, R., y González, D. (2012). Productividad y Competitividad [Recurso de Aprendizaje]. Recuperado de http://nulan.mdp.edu.ar/1607/1/02 productividad competitividad. pdf

Caves, R. (1980). Industrial Organization, Corporate Strategy and Structure. Journal of Economic Literature, 18(1), 64-92. doi: https://doi.org/10.1007/978-1-4899-7138-8_16

Chavarría, C.R. (2009). Estudio sobre turismo rural en Costa Rica [Documento de Trabajo]. San José, Costa Rica: IICA. Recuperado de https://hopelchen.tecnm.mx/principal/sylabus/ fpdb/recursos/r88499.PDF

Che, D., Veeck, A. y, Veeck, G. (2005). Sustaining production and strengthening the agritourism product: Linkages among Michigan agritourism destinations. Agriculture and Human Values, 22, 225-234. doi: https://doi.org/10.1007/s10460-004-8282-0 
Coleman, J. (1988). Social capital in the creation of human capital. American Journal of Sociology, 94, S95-S120. Recuperado de https://www.jstor.org/stable/2780243

Coleman, S. (2002). Characteristics and Borrowing Behavior of Small, Women-Owned Firms: Evidence from the 1998 Survey of Small Business Finances. Journal of Business and Entrepreneurship, 14(2), 151-166. Recuperado de https://www.proquest.com/ openview/c4e4ec6bab818959d8053680b6d2f096/1?pq-origsite=gscholar\&cbl=33312

Coleman, S. (2007). The role of human and financial capital in the profitability and growth of women-owned small firms. Journal of Small Business Management, 45(3), 303-319. doi: https://doi.org/10.1111/i.1540-627X.2007.00214.x

Colin, F.L. y Aldekozea, I. (2004). Sistematización de la experiencia del ecoturismo comunal como una alternativa económica para la protección del suelo, agua, aire y la biodiversidad en la microcuenca de Quebrada Arroyo, Savegre. San José: Programa de Pequeñas Donaciones, PNUD. Recuperado de http://alboan.efaber.net/ebooks/0000/0710/6 PNU SIS 2.pdf

Cooper, A., Gimeno Gascón, F., y Woo, C. (1997). Initial Human and Financial Capital as Predictors of New Venture Performance. The Journal of Private Equity, 1(2), 13-30. doi: https://doi.org/10.1016/0883-9026(94)90013-2

Creswell, J.W. (2014). Research Design: Qualitative, Quantitative, and Mixed Methods Approaches. Thousand Oaks, California: SAGE.

De La Fuente, S. (2011a). Análisis de conglomerados. Facultad de Ciencias Económicas y Empresariales, Universidad Autónoma de Madrid. Recuperado de http://www.fuenterrebollo.com/Economicas/ECONOMETRIA/SEGMENTACION/CONGLOMERADOS/ conglomerados.pdf

De Vita, L., Mari, M., y Poggesi, S. (2014). Women entrepreneurs in and from developing countries: Evidences from the literature. European Management Journal, 32(3), 451-460. doi: https://doi.org/10.1016/j.emj.2013.07.009

Debrah, Y.A. (2007). Promoting the informal sector as a source of gainful employment in developing countries: insights from Ghana. International Journal of Human Resource Management, 18(6), 1063-1084. doi: https://doi.org/10.1080/09585190701321716

Demirgüç-Kunt, A., Beck, T. y, Honohan, P. (2008). Finance for All? Policies and Pitfalls in Expanding Access. Washington, DC.: World Bank. Recuperado de https://openknowledge.worldbank.org/handle/10986/6905

Díaz, M.C., y Jiménez, JJ. (2010). Recursos y resultados de las pequeñas empresas: Nuevas perspectivas del efecto género. Cuadernos de Economía y Dirección de la Empresa, 13(42), 151-175. doi: https://doi.org/10.1016/S1138-5758(10)70006-2

Duarte, C.D., y Pereira, J.A.D. (2018). The role of women in rural tourism: a study in the Planaltina's Rajadinha circuit-Federal Districts. Revista Brasileira de Pesquisa em Turismo, 12(3), 81-102. doi: https://doi.org/10.7784/rbtur.v12i3.1446

Fabowale, L., Orser, B., y Riding, A. (1995). Gender, Structural Factors, and Credit Terms Between Canadian Small Businesses and Financial Institutions. Entrepreneurship Theory and Practice, 19(4), 41-65. doi: https://doi.org/10.1177/104225879501900404

Ferguson, L. (2010). Turismo, igualdad de género y empoderamiento de las mujeres en Centroamérica. Papeles de relaciones ecosociales y cambio global, (111), 123133. Recuperado de https://www.fuhem.es/media/cdv/file/biblioteca/PDF\%20 
Papeles/111/turismo igualdad de genero y empoderamiento mujeres Centroamerica_L. FERGUSON.pdf

Fletschner, D., Anderson, C.L., y Cullen, A. (2010). Are women as likely to take risks and compete? Behavioural findings from central Vietnam. The Journal of Development Studies, 46(8), 1459-1479. doi: https://doi.org/10.1080/00220381003706510

Fuentes, F.J., y Sánchez, S.M. (2010). Análisis del perfil emprendedor: una perspectiva de género. Estudios De Economía Aplicada, 28(3), 696-696. Recuperado de https://dialnet. unirioja.es/servlet/articulo?codigo $=3388507$

Getz, D., y Carlsen, J. (2005). Family business in tourism: State of the art. Annals of Tourism Research, 32(1), 237-258. doi: https://doi.org/10.1016/i.annals.2004.07.006

Gidarakou, I. (2015). Women's Entrepreneurshipin Rural Greece.InternationalJournalof Business and Management, 10(10), 129-142. doi: https://doi.org/10.1080/13608740903037968

Grant, R.M. (1991). The resource-based theory of competitive advantage: Implications for strategy formulation. California Management Review, 33(3), 114-135. doi: https://doi. org/10.2307/41166664

Hall, R. (1992). The strategic analysis of intangible resources. Strategic Management Journal, 13(2), 135-144. doi: https://doi.org/10.1002/smi.4250130205

Hallak, R., Assaker, G., y Lee, C. (2015). Tourism entrepreneurship performance: The effects of place identity, self-efficacy, and gender. Journal of Travel Research, 54(1), 36-51. doi: https://doi.org/10.1177/0047287513513170

Henry, C., Foss, L., y Ahl, H. (2015). Gender and entrepreneurship research: a review of methodological approaches. International Small Business Journal, 34(3), 217-241. doi: https:// doi.org/10.1177/0266242614549779

Hernández, V., Madrigal, J., Rodríguez, J.A., y Brenes, L. (2008). Hacia el estado de las MIPYMES: Primer diagnóstico nacional de MIPYMES. San José, Costa Rica: UNED. Recuperado de http://omipymes.uned.ac.cr/wp-content/uploads/2013/12/Cuadernillo-1-PrimerDiagnostico-Nacional-de-MIPYMES.pdf

Hill, C.W.L., y Jones, G.R. (2005). Administración estratégica: Un enfoque integrado. Bogotá, Colombia: McGraw-Hill.

Honig, B. (1998). What determines success? examining the human, financial, and social capital of jamaican microentrepreneurs. Journal of Business Venturing, 13(5), 371-394. doi: https://doi.org/10.1016/S0883-9026(97)00036-0

lakovidou, O., Koutsou, S., Partalidou, M., y Emmanouilidou, M. (2012). Women entrepreneurs in rural Greece: do they come from the same "neck of the woods"? Locals, daughters-in-law and urban-newcomers. New Medit, 11(2), 57-64. Recuperado de https:// dialnet.unirioja.es/servlet/articulo?codigo $=3987626$

Instituto Costarricense de Turismo. (2009). Anuario estadístico de turismo 2008. San José, Costa Rica: Unidad de Administración de la Información. Recuperado de https://www.ict. go.cr/es/documentos-institucionales/estad\%C3\%ADsticas/informes-estad\%C3\%ADsticos/anuarios/2005-2015/471-2008/file.html

Instituto Costarricense de Turismo. (2018a). Anuario estadístico de turismo 2017. San José, Costa Rica: Unidad de Administración de la Información. Recuperado de https:// www.ict.go.cr/es/documentos-institucionales/estad\%C3\%ADsticas/informes-estad\%C3\%ADsticos/anuarios/2005-2015/1103-2017-1/file.html 
Instituto Costarricense de Turismo. (2018b). Divisas por concepto de turismo. San José, Costa Rica: Planeamiento y Desarrollo Turístico. Recuperado de https://www.ict.go.cr/es/ documentos-institucionales/estad\%C3\%ADsticas/cifras-econ\%C3\%B3micas/costa-rica/960-divisas-por-concepto-de-turismo/file.html

Instituto Costarricense de Turismo. (2018c). Principales actividades realizadas por los turistas. Recuperado de https://www.ict.go.cr/es/estadisticas/cifras-turisticas.html

Instituto Nacional de Estadística y Censo. (2016). Manual de Clasificación Geográfica con Fines Estadísticos de Costa Rica. Recuperado de http://www.inec.go.cr/sites/default/files/ documetos-biblioteca-virtual/meinstitucionalmcgfecr.pdf

Jaafar, M., Rasoolimanesh, S., y Lonik, K. (2015). Tourism growth and entrepreneurship: Empirical analysis of development of rural highlands. Tourism Management Perspectives, (14), 17-24. doi: https://doi.org/10.1016/j.tmp.2015.02.001

Jóhannesson, G.P., Skaptadóttir U.D., y Benediktsson K. (2003). Coping with social capital? The cultural economy of tourism. Sociologia Ruralis, 43(1), 13-16. doi: https://doi. org/10.1111/1467-9523.00226

Knickel, K., y Renting, H. (2000). Methodological and conceptual issues in the study of multifunctionality and rural development. Sociologia ruralis, 40(4), 512-528. doi: https:// doi.org/10.1111/1467-9523.00164

Koutsou, S., Notta, O., Samathrakis, V., y Partalidou, M. (2009). Women's entrepreneurship and rural tourism in Greece: Private enterprises and cooperatives. South European Society and Politics, 14(2), 191-209. doi: https://doi.org/10.1080/13608740903037968

Lebendiker, M., Herrera, R. y Velásquez, G. (2015). Reporte Nacional 2014: la situación del emprendimiento en Costa Rica, una perspectiva local sobre emprendimientos, retos y crecimientos en Costa Rica. San José, Costa Rica: Asociación Incubadora Parquetec. Recuperado de https://www.gemconsortium.org/country-profile/53

Lerner, M., y Haber, S. (2001). Performance factors of small tourism ventures: The interface of tourism, entrepreneurship, and the environment. Journal of Business Venturing, 16(1), 77-100. doi: https://doi.org/10.1016/S0883-9026(99)00038-5

Ling, R.S.J., Wu, B., Park, J., Shu, H., y Morrison, A.M. (2013). Women's role in sustaining villages and rural tourism in China. Annals of Tourism Research, 43, 634-638. doi: https:// doi.org/10.1016/i.annals.2013.07.009

Meyer, N., y Mostert, C. (2016). Perceived barriers and success factors of female entrepreneurs enrolled in an entrepreneurial programme. International Journal of Social Sciences and Humanity Studies, (8)1, 48-66. Recuperado de http://repository.nwu. ac.za/handle/10394/24513

Organización Mundial del Turismo. (2018). El turismo y los Objetivos de Desarrollo Sostenible Buenas prácticas en las Américas. doi: https://doi.org/10.18111/9789284419937

Parsheera, C.M., y Sood, J. (2011). Participation of women in rural tourism in Kullu, HP. Tourism Development Journal, 9(1), 102-111. Recuperado de https://www.academia. edu/2069448/Parsheera_C.M. and Sood_J.2011.Participation of women in rural tourism in Kullu HP. Tourism Development Journal 9 | 102-111

Pena, I. (2002). Intellectual capital and business start-up success. Journal of Intellectual Capital, I. 3(2), 180-198. doi: https://doi.org/10.1108/14691930210424761 
Peña, D. (2013). Análisis de datos multivariantes. España: McGraw-Hill. Recuperado de https:// elibro.net.una.remotexs.co/es/lc/unacr/titulos/50267

Pérez, B., y Fuller, N. (2015). Turismo rural comunitario, género y desarrollo en comunidades campesinas e indígenas del sur del Perú. Quaderns de l'Institut Català d'Antropologia, (31), 95-119. Recuperado de https://dialnet.unirioja.es/servlet/articulo?codigo=5590153

Pérez López, C. (2004). Técnicas de análisis multivariante de datos: aplicaciones con SPSS. Pearson Educación. Recuperado de https://elibro.net.una.remotexs.co/es/lc/unacr/ titulos/45315

Powers, J., y Magnoni, B. (2010). Dueña de tu propia empresa: Identificación, análisis y superación de las limitaciones a las pequeñas empresas de las mujeres en América Latina $y$ el Caribe. Recuperado de https://publications.iadb.org/en/publication/13690/ duena-de-tu-propia-empresa-identificacion-analisis-y-superacion-de-las

Priem, R.L., y Butler, J.E. (2001). Is the resource-based "view" a useful perspective for strategic management research? Academy of Management Review, 26(1), 22-40. doi: https:// doi.org/10.5465/amr.2001.4011928

Radović, G., y Radović-Marković, M. (2016). Significance of rural tourism for female entrepreneurship development in the Republic of Serbia. Journal of Women's Entrepreneurship and Education, (3-4), 3-19. Recuperado de https://www.library.ien.bg.ac.rs/index.php/ iwee/article/view/260

Ramírez, L. (2010). La informalidad y semiformalidad empresarial en Costa Rica: Un acercamiento desde la mirada de personas expertas, San José, Costa Rica: UNED. Recuperado de: http://bibliotecacuc.ac.cr/cgi-bin/koha/opac-detail.pl?biblionumber $=8273$

Roberts, L. y Hall, D. (2001). Rural tourism and recreation: principles to Practise. Oxon, UK: CABI Publishing.

Saffu, K., Apori, S.O., Elijah-Mensah, A., y Ahumatah, J. (2008). The contribution of human capital and resource-based view to small- and medium-sized tourism venture performance in Ghana. International Journal of Emerging Markets, 3(3), 268-284. doi: https:// doi.org/10.1108/17468800810883684

Schmidt, C., Tomio, M., Demko Alves, J.K. y, Rossi, F. (2016). O empreendedorismo coletivo no contexto do turismo rural sustentável: Uma experiência do Sul do Brasil. Pasos, 14(5), 1161-1174. Recuperadodehttps://dialnet.unirioja.es/servlet/articulo?codigo=5685772

Shaw, E., Marlow, S., Lam, W., y Carter, S. (2009). Gender and entrepreneurial capital: Implications for firm performance. International. Journal of Gender and Entrepreneurship, 1(1), 25-41. doi: https://doi.org/10.1108/17566260910942327

SOFA Team. (2011). Gender differences in assets. Working paper No. 11-12. Rome, Italy: Agricultural Development Economics Division, FAO. Recuperado de http://www.fao. org/3/a-am317e.pdf

Solano Pachecho, L. (2006). Turismo Rural Comunitario en Costa Rica. Ambientico, (150), 9-13. Recuperado de https://www.ambientico.una.ac.cr/index.php/numeros-completos/ turismo-rural-en-costa-rica/

Teece, D.J., Pisano, G., y Shuen, A. (1997). Dynamic capabilities and strategic management. Strategic Management Journal. 18(7), 509-533. doi: https://doi.org/10.1002/ (SICI)1097-0266(199708)18:7<509::AID-SMJ882>3.0.CO;2-Z 
Tigges, L.M., y Green, G.P. (1994). Small business success among men- and women-owned firms in rural areas. Rural Sociology, 59(2), 289-310. doi: https://doi. org/10.1111/j.1549-0831.1994.tb00534.x

Tiwari, N., y Goel, G. (2017). Success factors of women owned micro and small enterprises in India. International Journal of Entrepreneurship and Small Business. 31(4), 590-608. doi: 10.1504/IJESB.2017.085424

Watson, J. (2003). Failure Rates for Female-Controlled Businesses: Are They Any Different? Journal of Small Business Management, 41(3), 262-277. doi: https://doi. org/10.1111/1540-627X.00081

Wernerfelt, B. (1984). A resource-based view of the firm. Strategic Management Journal, 5(2), 171-180. Recuperado de www.jstor.org/stable/2486175

World Bank. (2012). World Development Report 2012: Gender Equality and Development. Recuperado de https://openknowledge.worldbank.org/handle/10986/4391

\section{Contribución de los autores}

Todas las autoras han contribuido por igual en la elaboración del artículo. 